\title{
CHANGES IN THE DEMOGRAPHIC DETERMINANTS OF U.S. POPULATION MOBILITY: 1940-80
}

\author{
Michael J. White and Peter R. Mueser*
}

\begin{abstract}
As a rule of thumb, about one-fifth of all Americans change residence in a given year, and over the course of five years, about half of all persons change residence. While this generalization has remained roughly true over the last few decades, there have been appreciable shifts in the relative distribution among types of moves. Taking an integrated approach, we examine the choice to move locally, to migrate within a state, or to migrate between states over the period 1940-80. Using a multinomial logit model and U.S. census microdata, we test for the presence of changes in the determinants of residential mobility and migration and contrast such effects with the influence of shifting population composition. We demonstrate that the effects of age and education differ, sometimes appreciably, by type of mobility. There has been little change in the impacts of demographic characteristics on the propensities to make particular types of moves. Instead, we find that the increasing share of longer distance movement has been due to secular changes, most likely traced to improvements in transportation and communication, and a favorable shift in population composition, especially increased educational attainment. The association of demographic characteristics with intercounty and interstate change of residence has remained stable.
\end{abstract}

\section{INTRODUCTION}

A rule of thumb regarding population mobility in the United States is that about one-fifth of all Americans change residence in a given year, and that over the course of five years, about half of all persons change residence. It is often further remarked that the United States is an increasingly mobile society.

In fact, Table 1 shows that, as measured by simple change of residence, the five-year mobility level was 59 percent for the period 1935-40, declined to less than 44 percent in 1965-70, and increased slightly to 46 percent in 1975-80. However, there have been more significant shifts in type of move. In particular, the balance between short and long moves has shifted in favor of the latter. In 1980, according to the decennial census, of the adult population (aged 18 and over) who had changed residence since 1975 , over one-fifth of these made interstate moves. By contrast, in the 1940 census, only about one in ten moved between states. ${ }^{1}$

Three kinds of explanations-which are not mutually exclusive-may be offered to explain the shifts in overall mobility and type of mobility. First, changes

\footnotetext{
*Department of Sociology, Brown University, and Department of Economics, University of Missouri, respectively. Research reported here was supported by grant \#HD18739 from the National Institute of Child Health and Human Development. We thank Joseph Tiemey for his assistance with computer programming. Previous versions of this paper were presented to the Population Association of America and the Association of American Geographers.
} 
TABLE 1

Residential Mobility and Migration, by Decade, Ages 18 and Over

\begin{tabular}{lrrrrr}
\hline \hline & 1940 & $1950^{*}$ & 1960 & 1970 & 1980 \\
\hline Stay & 41.1 & 83.4 & 51.4 & 56.4 & 53.8 \\
Any Move & 58.9 & 16.6 & 48.6 & 43.6 & 46.2 \\
$\quad$ Intracounty & 47.2 & 11.7 & 30.7 & 24.5 & 24.7 \\
Intercounty, intrastate & 5.8 & 2.3 & 8.4 & 9.3 & 9.7 \\
Interstate & 5.9 & 2.6 & 9.5 & 9.8 & 11.9 \\
& & & & & \\
Number & 24,596 & 23,611 & 22,323 & 23,681 & 24,278 \\
\hline
\end{tabular}

*One-year mobility interval.

in demographic composition (e.g., educational attainment) occurring over this period may have induced changes. Second, changes in mobility patterns may be associated with secular developments that affect migration largely independently of the impact of demographic characteristics. Third, mobility changes may be associated with changes in the way particular demographic characteristics are associated with the probability of making a move. For example, the effect of an additional year of schooling on the probability of making an interstate move may itself have changed over time.

Whereas most studies of population movement look only at a binary decision of making a local move versus staying (migrants omitted), or of migrating versus staying or making a local move, our approach treats these outcomes jointly. Since the choice of migration-defining boundary is not obvious-in fact, there is evidence that the appropriate migration-defining boundary has itself shifted over time (White and Mueser 1988)-several levels of movement are examined simultaneously. ${ }^{2}$

While these three hypotheses are complementary, the accumulation of evidence favoring one over another is of some consequence. Secular changes would suggest an important role for technological (and perhaps social) change. Also important is the degree to which the mobility experiences of demographic groups defined by ascribed characteristics (race, gender) have converged or diverged and the degree to which returns to achieved characteristics (education) have altered over time. Stability would suggest that predictions of future mobility could rely on models of the past. Relatedly, an integrated approach should improve our understanding and predictive ability by more appropriately applying the same model to outcomes at different geographic levels. 
While work on the correlates and determinants of geographic mobility is voluminous (see Long 1988 for a discussion and review), only a small number of studies have considered the role of population composition in explaining changes in patterns of migration over time. Long (1973) compared mobility by education and age using 1935-40 and 1965-70 decennial census data. He concluded that about two-thirds of the increase in interstate migration rates among men aged 2534 over the period could be attributed to changes in the migration rates themselves, while one-third was accounted for by changes in the educational distribution. He also found that education was a poor predictor of short-distance mobility and suggested that education might be losing its ability to predict mobility. In his more recent census monograph, Long (1988) again returned to the topic. He observed that five-year interstate migration rates rose from the 1930 s to the 1950 s and rose again from the 1950 s to the 1960 s, but then fell between the 1960 s and the 1970s. He discussed several factors that could be responsible for the changes, including compositional changes. Long concluded that changes in the economic returns to education were largely responsible for the period swings in interstate migration (Long 1988, 45).

In this paper, we test for changes in the demographic determinants of U.S. local and long distance geographic mobility over the period 1940-80. The following section reviews some relevant aspects of the literature on the determinants of mobility and migration. Our empirical analyses begin with a discussion of the broad features of observed changes. We then apply the multinomial logit model to mobility, testing hypotheses about the determinants of migration and their changes. The final section of the paper comments on the changing relationship between personal characteristics and the observed levels of mobility in the population and draws some implications for general models of mobility.

\section{ANALYTICAL FRAMEWORK: COMPOSITIONAL VS. STRUCTURAL CHANGE}

We are interested in distinguishing the effects of changing population composition from the effects of "structural" changes in producing overall shifts in the mobility of the population. Changes in the composition of the population (aging, increasing educational attainment) may produce aggregate shifts in the distribution of types of mobility observed without changing the underlying model and its coefficients. We define structural changes to be those that operate through changes in the model itself. In this sense, then, structural change alters the equation predicting the probability of a particular type of move. 
Within the consideration of structural change, we draw a distinction between those forces that do not alter the relationship between individual level determinants of migration and those that do. In the former case, the influence would be seen through changes in the constant term in the equation. A number of societal developments in the period we examine impinge on the migration propensity of individuals but need not be reflected in observed relationships involving demographic characteristics. Important examples include extensive growth of transportation and communication networks over the 1940-80 period. Similarly, integration of regions within the United States would help to lower barriers to movement by reducing the cultural costs of relocation and by providing a national job market. These developments suggest that the constant terms in our estimation equation should change, reflecting the greater mobility of all persons. ${ }^{3}$

Altematively, structural changes may be manifest in changes in estimated coefficients for demographic traits. For instance, increasing labor market returns to educational skills would produce larger coefficients for the effect of educational attainment on the probability of interstate migration. A decline in racial discrimination would be expected to translate into a reduction in the magnitude of the coefficient on race for all types of mobility.

\section{Determinants of Mobility and Migration}

Our behavioral model of longer distance migration at each point in time is conventional, taken from demographic models and human capital theory. Much of the original conceptual work focussed on migration as a response to job search. More recently, the role of family and life cycle concerns have gained greater prominence (Greenwood 1985). Migration may be defined as longer distance residential relocation; with census information, it is usually defined to be movement across a county or state boundary. ${ }^{4}$

The probability of migration varies with age according to a regular schedule, similar in a variety of populations (Long 1988; Rogers and Willikens 1985). This age profile is, for the most part, consistent with human capital models of migration (Bowles 1970; Sjaastad 1963; Greenwood 1969, 1975). In multivariate models applied to populations of adults or household heads, age typically exerts a strong negative effect on the probability of making a move in a given year (Speare, Goldstein, and Frey 1974; Graves and Linneman 1979). The strong relationship of mobility with age appears to be itself closely linked to marriage and the presence of children (Sandefur 1985).

Human capital theory also points to education as a determinant of migration. Theory predicts that the more highly educated stand to gain more from a geographically extensive job search, even national in scope. They may benefit 
from a wider search because their skills may be more occupation specific (Schwartz 1976), and because their proportionately higher incomes may magnify dollar differences across locations. Simple univariate and bivariate tabulations from the U.S. census and survey sources indicate that, at every age, the more highly educated population is the more migratory, although not necessarily more mobile within counties (Long 1973; Greenwood 1975; Bogue 1985, 430). In multivariate models, however, the results are not always clear. DaVanzo (1976) found education differentials in family migration propensity, but the relationship was not monotonic. Graves and Linneman (1979), predicting the probability of any move, found education to have a negative effect as often as positive in several versions of the estimated model. Sandefur and Scott's (1981) most inclusive model reveals nonsignificant and small effects of education on the hazard rate for intercounty and interstate mobility.

Members of minority groups have access to fewer resources and face discrimination. Both operate to limit movement. Indeed, previous work has found that blacks are less migratory than whites, even upon controlling for socioeconomic status (Kaluzny 1975; Farley and Allen 1987). Historical differences across regions in levels of discrimination may have increased incentives for interregional migration in some periods. In the local movement case, too, the drain on resources represented by a residential move and the presence of discrimination would provide disincentives to relocation. Lower levels of income ownership among minorities, in contrast, are expected to increase local mobility levels.

Theory provides little guidance on the effects of gender on interregional migration. While migration differentials by sex have existed in many historical periods (Thomas 1938), such differences are now generally small in developed countries.

\section{Hypotheses}

We hypothesize that certain compositional changes in the United States from 1940-80 will be manifest in the changing distribution of persons across types of moves. The major change in population composition during the $1940-80$ period is the increase in the level of educational attainment in the population. We anticipate that this will shift the relative share of movement in favor of longer distances. Aging of the population would tend to reduce mobility, especially local mobility, where age effects are more visible (White and Mueser 1988). Mean age increased by just more than two years between 1940 and 1980, but in the population more than 35 years of age, the mean increased as much as four years over the time period. Still, net effects of the shift in age composition are expected to be modest. 
During this period of time, the proportion black in the population also increased by about one percentage point.

We hypothesize a convergence in the rates of black and non-black mobility, both intra- and interstate. As blacks become more economically and socially integrated into the mainstream (Fariey 1984; Smith and Welch 1986), and the mass movement of blacks out of the South is expended (Fligstein 1981; Farley and Allen 1987), we anticipate that differentials would decline.

The growth of a national labor market with demands for highly skilled individuals suggests that we would observe increases in the return to (and propensities for) migration with education. For the impact of education on migration to increase over time, educated individuals must receive greater rewards for searching these national labor markets. The change in the migration coefficient represents a test of the extent to which education has become of more general value across regions.

The increasing educational attainment of the population is anticipated to produce a secondary impact on the age profile of migration. Since the completion of formal education and the entry into the full-time labor force now occurs later in life, the peak years of migratory behavior can be expected to shift upward. The pursuit of higher education itself would be expected to promote migration, as many high school graduates migrate to attend college, and then migrate again upon receipt of degree. In addition, longer life spans could promote increased mobility (local and migratory), because there would be a longer time to recoup the expenses, both monetary and psychological, of relocation.

\section{DATA AND METHODS}

The data for this analysis are subsamples drawn from the public use microdata samples (PUMS) of the decennial censuses of 1940, 1960, 1970, and 1980 (U.S. Bureau of the Census 1972, 1975, 1983a, 1983b). Not all of the same characteristics are available in each of the PUMS files, reflecting changes both in content of the census schedule and processing of the information. There is very little change over time in the coding or interpretation of the mobility variables or demographic characteristics, however. The measurement of residential mobility is based on the comparison of census residence with reported place of residence five years earlier. (In 1950, the reference interval is one year, so we omit those data from the statistical analysis.) For each decade, we divide our sample into nonmovers, local (intracounty) movers, intercounty (intrastate) movers, and interstate movers. We restrict our population universe to those persons who were aged 18+ at the time of the census and who were residents of the United States in the refer- 
ence year. ${ }^{5}$ of course, retum migration and other multiple moves within the migration interval are not recorded.

We employ a multinomial logit model with these four categories of mobility to be predicted from the personal characteristics of the sampled individual. $P_{\mathrm{ij}}$, the probability that individual $i$ makes move type $\mathrm{j}$, is given as

$$
P_{i j}=\frac{e^{x_{i} B_{j}}}{\sum_{k=1}^{4} e^{x_{i} B_{k}}}
$$

where

$x_{i}$ is a vector of characteristics of person $i$, for which the first element is a constant,

$B_{j}$ is a vector of corresponding coefficients associated with choice $\mathrm{j}$,

$\mathrm{j}, \mathbf{k}=1, \ldots 4$ denote
(1) no move,
(2) intracounty move,
(3) intercounty-intrastate move, and
(4) interstate move.

Here we take the reference category to be nonmovers, so that $\mathrm{B}_{1}=0$ by construction. Estimates are obtained by maximization of the likelihood function (for more details, see Judge et al. 1985; McFadden 1974; Hensher and Johnson 1981). ${ }^{6}$

Since our data derive from decennial census sources, characteristics of the individuals are measured at the end of the mobility interval. This opens up the possibility of bias in the measurement of the effects of those characteristics that could change over the interval and be influenced by mobility. Because our interest centers on the association between basic demographic traits and population redistribution, we focus primarily on attributes of individuals that cannot change or are unlikely to change in response to mobility: age, sex, race,-and education. Since, for those who move to attend school, increases in education over an interval may be associated with mobility, we have split the sample at 30 years of age and estimated the model for each subsample. We also tested for interactions among age, education, and race, added to the simpler model, but rarely were these statistically significant. Except for an age-education interaction, they were dropped from later estimations. Although we do not report results in detail, we also estimated models that included family characteristics, labor force informa- 
tion, and housing tenure-attributes that are more likely to have changed in response to mobility over the five-year interval. ${ }^{7}$

We examined several specifications in order to sort out the influence of time period and age group. In each case, the basic demographic model includes effects of age (captured by a quadratic function), education (years of schooling), race (dummy for black), sex (dummy for female), and the interaction of age and education, with all models estimated for two age strata (18-29 and 30+). We also varied the equations with respect to time period. First, we pooled all years of data with no measures for time, thereby forcing coefficients and intercepts to be identical for each decade. Second, we allowed for period dummies only. Such a model assumes a linear change in the effects of the regressors over time, and the coefficients give the value of that yearly change. Finally, we estimated separate equations for each of the four periods. These allow us to perform statistical tests on the importance of various changes in intercepts and coefficients over time. Our test of relative explanatory power of nested models is the standard one, based on the difference in the log-likelihood between constrained and unconstrained models.

\section{RESULTS}

Table 2 presents goodness of fit measures for several equations, indicating the effects of pooling by age and by time period. The final three columns of the table indicate that we strongly reject the hypothesis of equality among the coefficients for the two age groups in each of the seven equations. In subsequent discussion, we treat the two groups separately.

Since our concerm focuses on the changes in the determinants of migration, we have performed a formal test of the changes in these parameters within each of the two age strata (lines 8-11). In each case, the increment in the log likelihood indicates that the unconstrained model provides a significantly better fit than the constrained model (line 1) for both age groups. In both cases, however, a sizable fraction of the improvement in fit is accounted for by changes in the intercepts, indicating a shift in underlying levels of mobility, net of other characteristics controlled in the model.

Basic Effects. Table 3 presents our estimates of the coefficients themselves for each age group and decade. Within the population 18-29, the two coefficients on age indicate that the probability of both local mobility and migration vs. stay is initially increasing and for most periods reaches a maximum in the mid-twenties. ${ }^{8}$ In this age stratum, blacks are generally less likely to make intercounty or interstate moves (statistically significant in half of the equations), while there is no generalizable pattem with respect to intracounty mobility. Females are more 


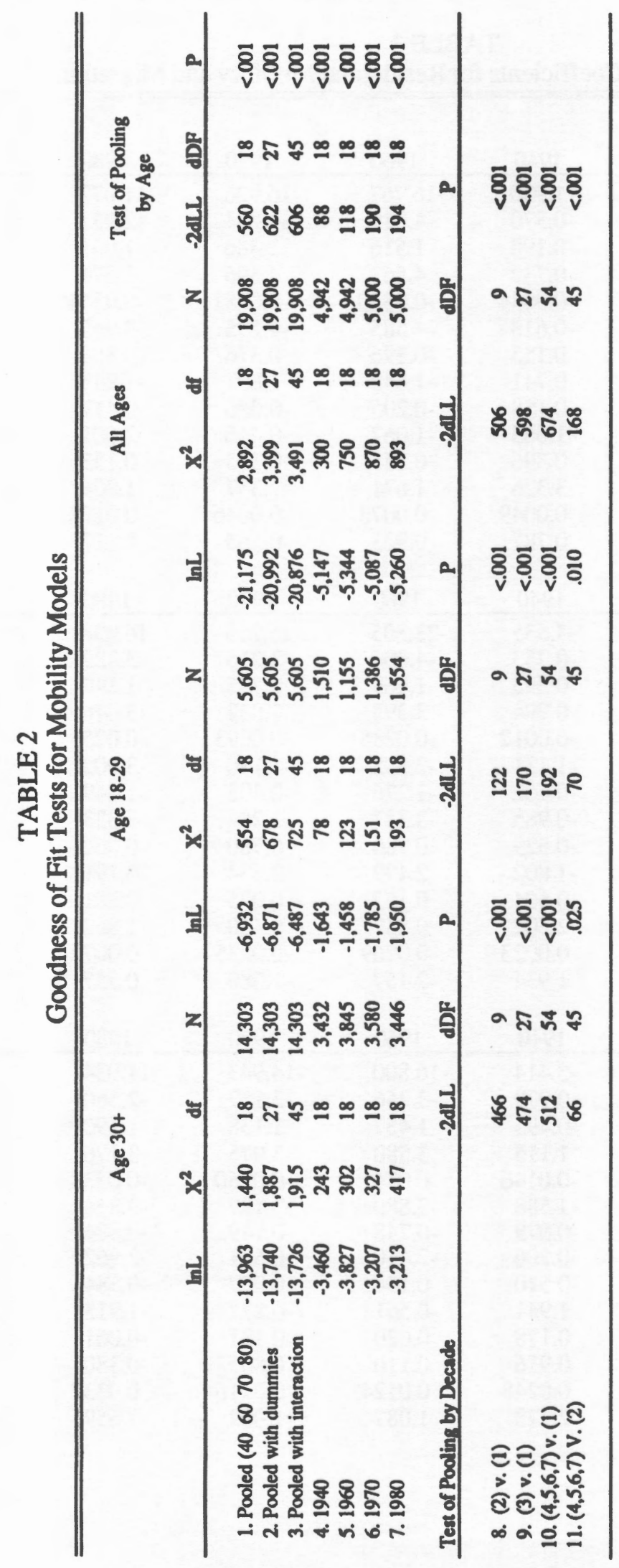


TABLE 3

Multinomial Logit Coefficients for Residential Mobility and Migration

\begin{tabular}{|c|c|c|c|c|}
\hline $\begin{array}{l}\text { Ages 18-29 } \\
\text { A. Intrecounty }\end{array}$ & 1940 & 1960 & 1970 & 1980 \\
\hline \multirow[t]{2}{*}{ Constant } & -1.930 & -16.767 & -16.926 & -11.072 \\
\hline & -0.570 & -4.019 & -4.274 & -2.957 \\
\hline \multirow[t]{2}{*}{ Age } & 0.198 & 1.516 & 1.386 & 1.061 \\
\hline & 0.732 & 4.563 & 4.396 & 3.674 \\
\hline \multirow[t]{2}{*}{$\mathrm{Age}^{* * 2}$} & -0.0034 & -0.0320 & -0.0281 & -0.0244 \\
\hline & -0.618 & -4.585 & -4.235 & -3.945 \\
\hline \multirow[t]{2}{*}{ Black } & 0.155 & -0.396 & 0.376 & -0.364 \\
\hline & 0.741 & -1.842 & 1.807 & -1.943 \\
\hline \multirow[t]{2}{*}{ Education (years) } & -0.158 & -0.205 & -0.086 & -0.417 \\
\hline & -1.063 & -1.067 & -0.446 & -2.001 \\
\hline \multirow[t]{2}{*}{ Female } & 0.396 & 0.255 & 0.325 & 0.133 \\
\hline & 3.326 & 1.671 & 2.357 & 1.004 \\
\hline \multirow[t]{2}{*}{ Age*Educ. } & 0.0049 & 0.0073 & 0.0046 & 0.0178 \\
\hline & 0.787 & 0.923 & 0.565 & 2.117 \\
\hline \multicolumn{5}{|l|}{ Ages 18-29 } \\
\hline B. Intercounty & 1940 & 1960 & 1970 & 1980 \\
\hline \multirow[t]{2}{*}{ Constant } & -4.535 & -23.305 & -16.255 & -16.238 \\
\hline & -0.733 & -4.006 & -3.216 & -3.332 \\
\hline \multirow[t]{2}{*}{ Age } & 0.393 & 1.469 & 0.775 & 1.149 \\
\hline & 0.794 & 3.395 & 2.032 & 3.076 \\
\hline \multirow[t]{2}{*}{ Age $^{* *^{2}}$} & -0.0012 & -0.0235 & -0.0093 & -0.0255 \\
\hline & -1.131 & -2.655 & -1.140 & -3.002 \\
\hline \multirow[t]{2}{*}{ Black } & -0.462 & -1.276 & -0.403 & -1.049 \\
\hline & -0.985 & -3.337 & -1.284 & -3.323 \\
\hline \multirow[t]{2}{*}{ Education (years) } & -0.529 & 0.780 & 0.780 & -0.062 \\
\hline & -1.802 & 2.499 & 2.534 & 0.191 \\
\hline \multirow[t]{2}{*}{ Female } & 0.504 & 0.165 & 0.075 & 0.301 \\
\hline & 2.302 & 0.857 & 0.450 & 1.869 \\
\hline \multirow[t]{2}{*}{ Age*Educ. } & 0.0023 & -0.0269 & -0.0235 & 0.0072 \\
\hline & 1.934 & -2.157 & -1.880 & 0.557 \\
\hline \multicolumn{5}{|l|}{ Ages 18-29 } \\
\hline C. Interstate & 1940 & 1960 & 1970 & 1980 \\
\hline \multirow[t]{2}{*}{ Constant } & -5.414 & -16.800 & -14.943 & -11.934 \\
\hline & -0.979 & -3.256 & -3.157 & -2.560 \\
\hline \multirow[t]{2}{*}{ Age } & 0.495 & 1.457 & 1.138 & 1.190 \\
\hline & 1.115 & 3.580 & 3.075 & 3.176 \\
\hline \multirow[t]{2}{*}{$\operatorname{Age}^{* * 2}$} & -0.0146 & -0.0341 & -0.0260 & -0.0338 \\
\hline & -1.588 & -3.889 & -3.197 & -3.854 \\
\hline \multirow[t]{2}{*}{ Black } & -0.079 & -0.748 & -0.149 & -0.884 \\
\hline & -0.206 & -2.410 & -0.531 & -2.962 \\
\hline \multirow[t]{2}{*}{ Education (years) } & -0.510 & -0.154 & -0.077 & -0.584 \\
\hline & -1.941 & -0.561 & -0.277 & -1.913 \\
\hline \multirow[t]{2}{*}{ Female } & 0.178 & 0.020 & 0.131 & -0.061 \\
\hline & 0.916 & 0.110 & 0.805 & -0.380 \\
\hline \multirow[t]{2}{*}{ Age*Educ. } & 0.0248 & 0.0124 & 0.0116 & 0.0332 \\
\hline & 2.273 & 1.087 & 1.002 & 2.659 \\
\hline
\end{tabular}


TABLE 3 (Continued)

Multinomial Logit Coefficients for Residential Mobility and Migration

\begin{tabular}{|c|c|c|c|c|}
\hline $\begin{array}{l}\text { Ages } 30+ \\
\text { A. Intracounty }\end{array}$ & 1940 & 1960 & 1970 & 1990 \\
\hline Constant & $\begin{array}{l}3.579 \\
5.266\end{array}$ & $\begin{array}{l}3.647 \\
4.866\end{array}$ & $\begin{array}{l}5.014 \\
5.943\end{array}$ & $\begin{array}{l}4.316 \\
4.747\end{array}$ \\
\hline \multirow[t]{2}{*}{ Age } & -0.108 & -0.134 & -0.201 & -0.190 \\
\hline & -4.700 & -5.632 & -7.974 & -7.049 \\
\hline \multirow[t]{2}{*}{ Age**2 } & 0.0007 & 0.0010 & 0.0015 & 0.0015 \\
\hline & 3.617 & 5.007 & 7.886 & 7.408 \\
\hline Black & 0.387 & 0.165 & 0.349 & 0.174 \\
\hline \multirow{2}{*}{ Education (years) } & $\begin{array}{r}2.754 \\
-0.015\end{array}$ & $\begin{array}{r}1.283 \\
-0.028\end{array}$ & $\begin{array}{r}2.413 \\
-0.018\end{array}$ & $\begin{array}{l}1.194 \\
0.014\end{array}$ \\
\hline & -0.357 & -0.671 & -0.368 & 0.856 \\
\hline \multirow[t]{2}{*}{ Female } & -0.127 & -0.165 & -0.166 & 0.013 \\
\hline & -1.707 & -2.186 & -1.901 & 0.313 \\
\hline \multirow[t]{2}{*}{ Age*Educ. } & 0.0000 & 0.0002 & -0.0000 & -0.0008 \\
\hline & -0.028 & 0.248 & -0.023 & -0.944 \\
\hline \multicolumn{5}{|l|}{ Ages 30t } \\
\hline B. Intercounty & 1940 & 1960 & 1970 & $19: 0$ \\
\hline \multirow[t]{2}{*}{ Constant } & 2.126 & -0.110 & 4.777 & 0.951 \\
\hline & 1.494 & -0.072 & 3.836 & 0.621 \\
\hline \multirow[t]{2}{*}{ Age } & -0.152 & -0.051 & -0.253 & -0.144 \\
\hline & -3.064 & -0.987 & -6.860 & -2.392 \\
\hline \multirow[t]{2}{*}{ Age**2 } & 0.0011 & 0.0002 & 0.0021 & 0.0009 \\
\hline & 2.498 & 0.489 & 7.338 & 2.497 \\
\hline \multirow[t]{2}{*}{ Black } & -0.066 & -0.554 & -0.289 & -0.220 \\
\hline & -0.203 & -1.900 & -1.016 & -0.862 \\
\hline \multirow[t]{2}{*}{ Education (years) } & -0.078 & 0.113 & 0.043 & 0.141 \\
\hline & 0.937 & 1.415 & 0.591 & 1.891 \\
\hline \multirow[t]{2}{*}{ Female } & -0.066 & -0.219 & -0.183 & -0.113 \\
\hline & -0.423 & -1.636 & -1.317 & -0.816 \\
\hline \multirow{2}{*}{ Age*Educ. } & -0.0006 & -0.0023 & -0.0007 & -0.0027 \\
\hline & -0.360 & -1.432 & -0.484 & -1.823 \\
\hline \multicolumn{5}{|l|}{ Ages 30t } \\
\hline \multirow[t]{2}{*}{ Constant } & 2.209 & 0.479 & 1.962 & -0.767 \\
\hline & 1.714 & 0.341 & 1.337 & -0.523 \\
\hline \multirow[t]{2}{*}{ Age } & -0.174 & -0.137 & -0.182 & -0.111 \\
\hline & -4.013 & -3.054 & -4.086 & -2.522 \\
\hline \multirow[t]{2}{*}{$\mathrm{Age}^{* * 2}$} & 0.0014 & 0.0012 & 0.0015 & 0.0011 \\
\hline & 3.746 & 3.444 & 4.268 & 3.260 \\
\hline \multirow[t]{2}{*}{ Black } & 0.504 & -0.203 & 0.105 & -0.234 \\
\hline & 1.790 & -0.735 & 0.395 & -0.895 \\
\hline \multirow[t]{2}{*}{ Education (years) } & 0.103 & 0.237 & 0.153 & 0.276 \\
\hline & 1.355 & 3.226 & 1.849 & 3.911 \\
\hline \multirow[t]{2}{*}{ Female } & -0.365 & -0.233 & -0.086 & -0.229 \\
\hline & -2.342 & -1.745 & -0.597 & -1.699 \\
\hline \multirow[t]{2}{*}{ Age*Educ. } & -0.0003 & -0.0028 & -0.0016 & -0.0032 \\
\hline & & & -0.970 & -2.393 \\
\hline
\end{tabular}

Note: $t$-statistics appear beneath the coefficients. 
mobile than males, although statistical significance is achieved for only a few of these coefficients. The difference is more marked the shorter the move. ${ }^{9}$ In our specification, the effect of education may depend on age. In most decades, and throughout most of the age range 18-29, greater education predicts a greater probability of making an intercounty or interstate move. The interaction coefficient is positive in six out of eight cases, indicating that the effect of education increases with age. ${ }^{10}$ However, for intercounty moves in $1955-60$ and 1965-70, the coefficient is negative, implying the education effect declines with age up to age 30 .

The lower panel of Table 3 indicates that the impacts of personal characteristics differ in the older age stratum, as would be expected from the strong rejection of the hypothesis of equivalence of the models by age group. In this case, the probability of making any move declines with age, yet the steepness of the decline itself is reduced with age. ${ }^{11}$ As individuals settle, following a period of high mobility in early adulthood, their probability of moving or migrating continues to decline, with movement due to retirement, empty-nest rehousing, and movement for long-term care tending to raise the probability of movement slightly from the linear age trend. Interestingly, we do not observe any appreciable differentiation in the age pattern across mobility types.

A modest racial differential in mobility appears in this age stratum, too, with blacks more likely to engage in local mobility, less likely to be intercounty migrants, and with no clear distinction evident among interstate migrants. Women are generally less mobile in this age stratum, an effect most pronounced for interstate migration. Consistent with the theoretical expectations and findings from previous research, our results indicate that the more highly educated are more likely to migrate, a differential that is greater for the longer distance moved. For interstate migration, the impact of education is positive throughout the working life, although it decreases with age. In contrast, for intercounty migration, although the impact as of 1960 is positive at age 30 , it is negative by age 65 . For local mobility, the impact of education is negative at all ages, although the size of the effect is substantively small.

These basic findings generally are consistent with the literature on residential mobility and migration, but our modelling allows us to more precisely separate out the effects of personal characteristics on different kinds of mobility events. Specifically, we observed (1) less age differentiation across mobility types than expected, (2) education matters considerably more for longer distance movement, and (3) unanticipated differences in the effect of gender on local and long distance mobility.

Time Trends. Even though we could reject the hypothesis of the equivalence of the coefficients of the regressors across different decades (1940-80), much of the difference across equations was accounted for by changes in the intercepts 
alone. While an examination of individual coefficients in Table 3 points to differences by decade, we can discern no appreciable time trends in the influence of personal characteristics on the probability of making certain types of moves. For example, contrary to our hypothesis of the convergence of black and non-black mobility pattems, we find that in the older stratum the greater probability of a black individual making a local move decreased from 1940 to 1960 , increased by 1970 , and decreased again by 1980 . A similar seesaw pattern is seen for interstate migration. ${ }^{12}$

An examination of Equation 2 of Table 2 (coefficients not shown), which pools samples across periods and includes a dummy for each decade, does indicate an appreciable shift over time in the underlying probability of undertaking certain kinds of moves. Within the younger age stratum, the constant terms in the intracounty equation indicate that, for the reference individual, the probability of making an intracounty move (vs. stay) declined steadily from 1940 to 1980. A similar pattem is found for intercounty migration and interstate migration although in neither case is the change statistically significant. For the older age stratum, the pattem of constant terms indicates that the relative probability of intracounty and intercounty moves has grown slightly over time, while the respective probability for interstate mobility has declined, although none of these changes is statistically significant. ${ }^{13}$

\section{COMPOSITIONAL CHANGE VS. STRUCTURAL CHANGE}

A major concern of the present paper is the relative importance of population composition versus "structural" shifts in underlying relationships in explaining changes in the probability of making different kinds of moves. Having concluded that there is little evidence for changes in the effects of individual characteristics on mobility, we now turn our attention to assessing the impact of changing population composition.

The major change in population composition during the $1940-80$ period is the increase in the level of educational attainment in the population, rising from 9.8 years to 12.4 years in the younger stratum and from 8.1 years to 11.6 years in the older stratum. Mean age in the younger stratum remained just above 23 years, while in the older stratum mean age increased slightly from 47.9 years in 1940 to 52.0 years in 1970 , declining slightly to 51.5 years in 1980 . Between 1940 and 1980, the proportion within the younger stratum grew from 30.5 percent to 31.1 percent. During this period of time, the proportion of blacks in the population also increased by about one percentage point. 
As a concise summary of our findings, we present Table 4, in which the effects of changing demographic composition and time period can be viewed. We make these calculations from the equation that pools the data from all census samples. It constrains coefficients to be the same for each of the basic demographic characteristics, but it does allow for a differing constant (dummy) for each decade. Line 1 of the table presents the odds of the several types of moves as observed in the 1940 data. ${ }^{14}$ Line 2 of the table presents the corresponding expected odds obtained by substituting the mean values of the 1940 characteristics into the equation. (In the multinomial logit model, substitution of regressor means does not necessarily reproduce the sample means.) Subsequent lines convert 1940 sample values to 1980 values successively for the characteristics listed. Line 7 introduces the secular (dummy variable) effects for 1980, and line 8 lists the observed values in the 1980 sample.

TABLE 4

The Effects of the Population Composition on the Odds of Spatial Mobility

\begin{tabular}{lccccc}
\hline \hline & \multicolumn{4}{c}{ Versus Stay } & \\
\cline { 2 - 5 } & $\begin{array}{c}\text { Any } \\
\text { Move }\end{array}$ & $\begin{array}{c}\text { Intra- } \\
\text { county }\end{array}$ & $\begin{array}{c}\text { Inter- } \\
\text { county }\end{array}$ & $\begin{array}{c}\text { Inter- } \\
\text { state }\end{array}$ & $\begin{array}{c}\text { Interstate } \\
\text { versus } \\
\text { Intracounty }\end{array}$ \\
\hline 1. Observed & 1.497 & 1.178 & 0.150 & 0.169 & 0.143 \\
2. 1940 Means & 1.657 & 1.373 & 0.125 & 0.158 & 0.115 \\
3. 1980 Age & 1.491 & 1.247 & 0.107 & 0.137 & 0.110 \\
4. 1980 Education & 1.553 & 1.214 & 0.133 & 0.206 & 0.169 \\
5. 1980 Race & 1.573 & 1.236 & 0.131 & 0.206 & 0.166 \\
6. 1980 Sex & 1.569 & 1.234 & 0.130 & 0.205 & 0.166 \\
7.1980 Effect & 0.862 & 0.533 & 0.153 & 0.176 & 0.330 \\
8. Observed 1980 & 0.842 & 0.473 & 0.180 & 0.189 & 0.399 \\
\hline
\end{tabular}

The change in age composition of the population between 1940 and 1980 makes for lower levels for all three types of mobility, with the odds of any kind of move declining from 1.66 to 1.49 . The aging of the population by 1980 also serves to make longer distance moves slightly less likely, given that an individual moves. Structurally, this age effect works through several avenues. Three variables included in the equation are influenced by age composition: the linear age measure, age-squared, and the age-education interaction. ${ }^{15}$ In addition, the equations for the two age strata are weighted by the proportion of the population in each group, so line 3 applies the 1980 weights, which favor the younger population.

The shift in educational distributions over the 40-year interval also produces a measurable shift in the mobility of the population. The rise in mean educational 
attainment (2.6 years in the younger stratum and 3.5 in the older) serves to make the population more mobile overall, with the total odds rising to 1.55 , recovering about a third of the downward effect of age changes. More notable, however, is that the increasing educational attainment has served to make the population much more migratory, given mover status. Column 5 indicates that a 50 percent increase in the odds of interstate migration (vs. intracounty move) is attributable to this secular rise in education.

A further example may help indicate the effect of increased educational attainment. ${ }^{16}$ Consider the expected mobility of a white male aged 35 . In 1940 , such an individual with eight years of education (near the mean) would have an expected odds of local mobility of 1.77 ; by 1980 , the odds would have declined to 0.53 . With 12 years of education (near the 1980 mean), the respective values would be 1.68 and 0.50 , respectively. Given the small negative influence that education has on the probability of making a local move, increases in levels of education over time play a small role. In contrast, the odds of an interstate move for such an individual with eight years of education are 0.24 in 1940 and 0.13 in 1980; for 12 years of education, the respective odds are 0.34 and 0.24 . Thus, for the example individual, the increase in schooling has a substantial effect on the probability of interstate migration, large enough to just offset the decline in the general propensity.

Little effect on mover status or the relative odds by distance is discemible from the change in the race or sex composition of the population.

The time period effect itself is substantial, as indicated by comparison of rows 6 and 7 in Table 4. For the mean person, the 1980 equation indicates the odds of making any move are 0.86 , as compared to the value of 1.6 as calculated from the 1940 equation with 1980 means substituted for age, education, race, and sex. Similarly, the odds of making a local move (vs. stay) are much lower in 1980 than predicted by 1980 characteristics in the 1940 equation. Most notably, the 1980 effect serves to shift the odds of movement in favor of longer distances, so that the odds of migration versus local movement are doubled beyond those that would be predicted based on compositional effects.

A rough decomposition of the differences between 1940 and 1980 migration shows that changes in demographic characteristics have a much smaller impact on general population mobility than on the type of movement. Comparison of rows 2 and 7 in column 1 indicates a decline by 1980 in the odds of making a move to about 52 percent of its former level. The age effects represent a decline to about 90 percent, and after education effects are added, the odds are at about 94 percent of the original level. After slight increases for race and sex, almost all of the remaining decline is in the decade specific effect. The odds of interstate versus intracounty moves (column 5) tell a different story. The age effects represent a 
decline to 96 percent of 1940 levels; education effects increase it to 145 percent, and decade effects raise it further to 287 percent of its 1940 level.

\section{CONCLUSION}

Our objective has been twofold. First, we placed the analysis of population mobility into a framework that allows the simultaneous analysis of altemative mobility decisions. We have examined the choice to move locally, to migrate within a state, or to migrate between states using a multinomial logit model. Second, we tested for changes in the determinants of geographic mobility and contrasted the impact of such changes with that of shifting population composition.

Although our basic results are consistent with the literature on the relationship between demographic characteristics and change of residence, our model suggests ways to amend this thinking. Our results recapitulate the basic age profile of population mobility but indicate further how this profile varies by type of move and by time, controlling for other characteristics. Our results also suggest the benefits that accrue by taking more care to specify type of move.

Educational attainment promotes migration, but not local mobility, as theory would predict. Moreover, the influence of education declines with age. Blacks are less mobile and migratory overall, but we found no discemible time trend in racial differentials. In results we did not anticipate, females were slightly more locally mobile than males and less migratory, again with no apparent time trend.

We find evidence of what might be termed "structural change" only in that we can reject the hypothesis of the equivalence of the models from decade to decade within each age stratum. It is the case, however, that much of this change is absorbed by shifts in the constant terms in the model; the effects of few personal characteristics change in systematic ways. Overall, it would appear that the increasing relative importance of migratory movement has been due to some secular changes and a favorable shift in educational attainment, while the relative role of demographic characteristics in explaining intercounty and interstate mobility has not changed.

\section{ENDNOTES}

1. These are tabulations from the respective microdata files using county and state boundaries. The published 1940 census tabulation uses a slightly different geographic scheme. 
2. The character of population exchange among regions and ecological areas has also shifted (Frey 1987; Wilson 1987). Long (1988) notes that the Census Bureau does not formally designate a migration-defining boundary, although it usually relies upon the county boundary convention.

3. For mobility within individual labor markets (counties and metropolitan areas), however, the effect may be less strong or even reversed, as declines in transportation and communication costs allows some individuals to substitute longer commutation for residential relocation following a job change.

4. Clark (1986) considers migration to be a move too far to continue commuting to the same job; more generally, it may be considered a change of labor market.

5. There have been some minor changes in the classification of "usual" place of residence. For instance, prior to 1950 students enrolled in college were classified as living at their parents home, rather than in their place of schooling. The increase in the ownership of second homes and seasonal migration could, presumably, further complicate the picture. Overall, though, these changes are not substantial. Microdata files allow consistent coding across censuses where published tabulations are not consistent. For example, in 1940 relocation across a central city boundary (within a designated metropolitan area) was counted as migration in published tabulations.

6. The multinomial logit model assumes that the odds of making one choice rather than another are independent of the odds of making a third choice. For this to hold, there can be no pair of alternatives that are particularly close substitutes. Maximum likelihood routines in SAS were used to calculate estimates of the parameters.

7. Other characteristics of individuals are available in census data. We have found that the inclusion of income and occupation contributes little to predicting population mobility. These measures apply to the end of the interval and thus may reflect the impact of migration. It may be the case that such factors measured at the start of the interval would influence mobility. Courgeau (1990), for instance, finds the timing of the measurement of marital status in relationship to mobility to be crucial.

8. The exception is that for 1940 mobility increases with age up to 29 for local and intercounty moves.

9. For ease of exposition, we consider intracounty moves to be of shorter distance than intercounty moves, which are, in tum, taken to be shorter than interstate moves.

10. For example, for those aged 23 in 1980 the increment to the log-odds (per year of educational attainment) is .104 for intercounty movement and .178 
for interstate movement, but for those age 29 , the increments are .147 and .379 , respectively.

11. The fitted function predicts reversals (critical points) within the life span, but for intercounty and interstate migration and for average educational levels, these generally occur only at or beyond the typical age of retirement.

12. We tested for time trends a second way. We pooled the equations by decade and interacted each demographic measure with time, thereby imposing the restriction of linear change in the parameters. These results (available from the authors) reinforce the impression of no identifiable trend in the values of the coefficients.

13. We estimated additional models that included other personal characteristics, variables that were less certain to reflect conditions prior to the event. These traits, measured as of the census date, include marital status, the presence of school-aged children, and home ownership. We found, contrary to expectation, that the never married were less likely to migrate in all four decades. The presence of children significantly reduced the probability of interstate migration in 1940,1960, and 1980. We found, as expected, that home ownership depressed geographic mobility and that its influence on mobility and migration generally declined over time.

14. These odds represent the probability of making the given move versus staying. The values have been calculated from the multinomial logit equation, which has been estimated with the reference group taken to be those who do not move.

15. In this last term, we estimated the column 3 mean of this interaction as the mean of the product term for 1940 added to the product of the increment in the average age (1980 mean minus 1940 mean) and the 1940 education mean.

16. This example is taken from detailed calculations made from the separate equations for each year. A copy is available from the authors.

\section{REFERENCES}

Bogue, Donald J. The Population of the United States. New York: Macmillan, 1985.

Bowles, Samuel. "Migration as Investment: Empirical Tests of the Human Investment Approach to Migration." Review of Economics and Statistics 52 (November 1970): 356-62.

Clark, William A.V. Human Migration. Beverly Hills, Calif.: Sage, 1986. 
Courgeau, Daniel. "France." In International Handbook on Internal Migration, by C. B. Nam, W. J. Serrow, and D. F. Sly, 125-144. New York: Greenwood, 1990.

DaVanzo, Julie. Why Families Move: A Model of the Geographic Mobility of Married Couples. Santa Monica, Calif.: Rand Corp, 1976.

DaVanzo, Julie, and Walter R. Allen. The Color Line and the Quality of Life in America. New York: Russell Sage Foundation, 1987.

Fligstein, Neil. Going North: Migration of Blacks and Whites from the South, 1900-1950. New York: Academic Press, 1981.

Frey, William H. "Migration and Depopulation of the Metropolis: Regional Restructuring or Rural Renaissance?" American Sociological Review 52 (April 1987): 240-257.

Graves, Philip E., and Peter D. Linneman. "Household Migration: Theoretical and Empirical Results." Journal of Urban Economics 6 (1979): 383-404.

Greenwood, Michael J. "An Analysis of the Determinants of Geographic Labor Mobility in the United States." Review of Economics and Statistics 51 (May 1969): $189-94$.

. "Research on Internal Migration in the United States: A Survey." Journal of Economic Literature 13 (June 1975): 397-433.

. "Human Migration: Theory, Models and Empirical Studies." Journal of Regional Science 25 (1985): 521-544.

Hensher, David A., and Lester W. Johnson. Applied Discrete Choice Modelling. New York: Wiley, 1981.

Judge, G. G., W. E. Griffiths, R. C. Hill, and T-C. Lee. The Theory and Practice of Econometrics. New York: Wiley, 1985.

Kaluzny, R. "Interstate Migration by Poverty Status and Race." Review of Economics and Statistics 57 (August 1975): 269-74.

Long, Larry H. "Migration Differentials by Age and Occupation." Demography 10 (1973): 243-258.

. Migration and Residential Mobility in the United States. New York: Russell Sage, 1988.

McFadden, Daniel. "Conditional Logit Analysis of Qualitative Choice Behavior." In Frontiers in Econometrics, edited by P. Zarembka. New York: Academic Press, 1974.

Rogers, Andrei, and Frans Willikens. Migration and Settlement: A Multiregional Comparative Study. Dordrecht: D. Reidel, 1985.

Sandefur, Gary D. "Variations in Interstate Migration of Men Across the Early Stages of the Life Cycle." Demography 22 (August 1985): 353-366. 
Sandefur, Gary D., and Wilbur J. Scott. "A Dynamic Analysis of Migration: An Assessment of the Effects of Age, Family and Career Variables." Demography 18 (1981): 355-368.

Schwartz, Aba. "Migration, Age, and Education." Journal of Political Economy 84 (August 1976): 701-719.

Sjaastad, Larry. "The Costs and Returns of Human Migration." Journal of Political Economy 70 (October 1963): 80-93.

Speare, Alden, Sidney Goldstein, and William Frey. Residential Mobility, Migration and Metropolitan Change. Cambridge, Mass.: Ballinger, 1974.

Thomas, Dorothy Swaine. Research Memorandum on Migration Differentials. New York: Social Science Research Council, 1938.

U.S. Bureau of the Census. A Public Use Sample of Basic Records from the 1970 Census. Washington, D.C.: U.S. Bureau of the Census [machine readable data file and documentation], 1972.

A Public Use Sample of Basic Records from the 1960 Census. Washington, D.C.: U.S. Bureau of the Census [machine readable data file and documentation], 1975.

. Census of Population and Housing 1940: Public Use Microdata Sample. Washington, D.C.: U.S. Bureau of the Census [machine readable data file and documentation], 1983a.

. Census of Population and Housing 1980: Public Use Microdata Sample. Washington, D.C.: U.S. Bureau of the Census [machine readable data file and documentation], 1983b.

White, Michael J., and Peter R. Mueser. "Implications of Boundary Choice for the Measurement of Migration and Residential Mobility." Demography 25 (August 1988): 443-459.

Wilson, Franklin D. "Metropolitan and Nonmetropolitan Migration Streams: 1935-1980." Demography 24 (May 1987): 211-22. 